\title{
In support of consumer-based strategy research
}

\author{
John Deighton ${ }^{1}$
}

Published online: 22 February 2016

(C) Academy of Marketing Science 2016

Rob Palmatier has invited me to comment on Rebecca Hamilton's editorial on consumer-based strategy. It is a provocative paper, in the sense that there are arguments on both sides of the claim. Let me say, to avoid suspense, that I end up on the writer's side.

Part of the editorial's argument is that researchers should think of $J A M S$ as an outlet for papers that study the consumer as the unit of analysis. Here a case can be made for the alternative view, that journals should be communities of disciplinary practice, so that research on the consumer is best published in consumer journals. In fact, I wrote an editorial contending that it was not altogether a good thing when the Journal of Marketing and the Journal of Marketing Research began to go after papers that a decade before would have been acceptable only to the Journal of Consumer Research.

To recap that discussion, an editorial in the Journal of Marketing Research by Huber (2007) claimed that there was a "drive toward the center" among the Journal of Marketing Research, the Journal of Marketing, Marketing Science and the Journal of Consumer Research, contending that there has been an "erosion of the partitions that previously rationalized the premier journals." It described an increasingly competitive journal environment in which editors poach each other's territories. It identified some positive consequences for authors from this competition among journals. I responded (Deighton 2007) that there are also negative consequences. Specialization among journals leads to refinement of reviewing standards, which deepens the scrutiny that each

John Deighton

jdeighton@hbs.edu

1 Harvard Business School, Soldiers Field Road, Boston, MA 02163, USA paper receives and, paper by paper, builds the discipline's integrity. It is true as Huber says that when journals compete, authors win. But when authors win as a consequence of a journal's drive to the center, the win comes at the expense of the rationalized structure of sub-disciplines that make up the field. And, my argument ran, it is not just methodological rigor in the reviewing process that is compromised when journals become less specialized, but also theoretical rigor and what could be called the reviewers' command of substantive contribution. (See Exhibit 2 in McGrath and Brinberg (1983) for an illustration of these three lenses for evaluating research.)

That's where Hamilton's editorial gave me pause. Reviewers have never paid as much attention to whether a paper makes a substantive contribution as they have to method and theory. In fact if substantive contribution is read as the possibility that a paper will interest people in the profession of marketing, the record is not good. I would assert that even in journals that encourage authors to explain the relevance of their research to issues of professional practice, articles seldom win the attention of professional marketers or the journalists who find stories for them to read. And one might go further and ask whether, if journals care about substantive contribution, shouldn't they routinely assign a marketing professional as a reviewer? The editorial led me to think that the "partitions that previously rationalized" the structure of subdisciplines of which I was so defensive is not so rational after all. There has been no pressure on journals to specialize by substantive theme.

Hamilton's editorial points to an important gap, a substantive gap, in the line-up of marketing journals. It provokes the thought that there is a need for an outlet not specialized for consumer research per se, but for strategy informed by consumer research. It makes the case that such an outlet would not only be specialized by substantive field, but by method (multi- 
method) and by discipline (organizational strategy.) And it goes on to point out that JAMS is a logical candidate to fill that gap because $J A M S$ has a record of welcoming papers that use consumer research to generate strategic recommendations.

Just one issue remains to be addressed: how does the field develop depth in its scrutiny of the substantive dimension of strategy papers informed by consumer research, if substantive contributions have not in the past been the strong suit of the field? The problem to be solved here runs deep in the culture of scholarship, where more abstraction means more status. Among those who measure excellence by the lights of the root disciplines, substantive contribution weighs less than methodological or theoretical contribution. That marketing scholarship is in the service of the profession of marketing is nothing a scholar wants to hear. We prefer to think of ourselves as economists, econometricians, psychologists, sociologists, and so on, who just happen to work in business schoolsand who wouldn't want to, given the pay differential.

It might help to interrogate why business schools are such comfortable places to live. I would suggest it is because we give the profession something it values and is willing to pay us for (indirectly, by valuing the students we educate). Unless business school cultures, particularly in marketing, come to see that our constituency is the profession of marketing, and the profession's highest standards and toughest problems are our standards and problems, it will be difficult for the validityenhancing process that is science to move us along the path to really useful consumer-based strategy research.

\section{References}

Deighton, J. (2007). The territory of consumer research: walking the fences. Journal of Consumer Research, 34(3), 279-282.

Huber, J. (2007). Journal of marketing research in the new competitive journalistic environment. Journal of Marketing Research, 44(1), 1-3.

McGrath, J. E., \& Brinberg, D. (1983). External validity and the research process: a comment on the Calder/Lynch dialogue. Journal of Consumer Research, 10(1), 115-124. 